\title{
Analyses of Tidal Fluctuations of Groundwater Discharge
}

\author{
Naoji Koizumi \\ Tottori Observatory, Research Center for Earthquake Prediction, \\ Disaster Prevention Research Institute, Kyoto University, \\ Tottori 680 , Japan
}

\begin{abstract}
Groundwater discharge, temperature and electrical conductivity of an artesian well were measured at Nishiawakura, Okayama Prefecture, southwest, Japan. The groundwater discharge showed tidal fluctuations of about $50 \mathrm{~cm}^{3} / \mathrm{s}$ induced by the tidal strain. Although the groundwater temperature also reflected the same tidal fluctuations as the discharge, the electrical conductivity did not manifest any tidal fluctuations. The discharge response to the tidal strain for the diurnal frequency constituents is different from that for the semi-diurnal frequency constituents. The response theory of a partially confined aquifer to the tidal strain, which has been used for explanation of the well water level fluctuations, can quantitatively explain these fluctuations of the discharge. It seems important that the theory could also be applied to the real groundwater flow fluctuations induced by the crustal strain because the strain-induced groundwater movement is considered to have close relation to geothermal and geochemical precursors to earthquakes.
\end{abstract}

\section{Introduction}

Earthquake-related chemical and temperature changes in groundwater have been often reported. It is said that the crustal strain changes induced by neighboring impending earthquakes cause anomalous groundwater movement which may in turn cause detectable chemical and temperature changes in the groundwater. In fact, many artesian wells show water level fluctuations induced by tidal strain. These fluctuations have been measured and examined to determine the elastic properties and porosity of aquifers by many researchers (e.g., Bredehoeft, 1967; Igarashi and Wakita, 1991; Melchior, 1960, 1983; Robinson and Bell, 1971; Rhoads and Robinson, 1979). But reports on well water discharge fluctuations induced by tidal strain have been scarce. Probably one of the main reasons is that well water discharge is not so easily measured as well water level. In order to study strain-induced groundwater movement, the careful observation of well water discharge induced by the tidal strain is clearly useful.

Tidal fluctuations of the groundwater discharge were measured at the Nishiawakura observation well, which is located in Okayama Prefecture, southwest, Japan. I also measured the temperature and electrical conductivity of the groundwater at the same well. In the present paper, I will show that the discharge response to the tidal strain

Received February 14, 1991; Accepted February 8, 1992 
has a kind of frequency dependence, and that the frequency dependence can be explained by the response theory of a partially confined aquifer to the tidal strain.

\section{Observations}

The Nishiawakura observation well $\left(35^{\circ} 11^{\prime} \mathrm{N}, 134^{\circ} 19^{\prime} \mathrm{E}\right)$ is located near the northwestern end of the Yamasaki Fault, an active left-lateral strike-slip fault in southwest Japan (Fig. 1). This fault zone was chosen as a test field for earthquake prediction research in 1978 and various kinds of observational studies have been conducted there (Kishimoto, 1981). The height of the observation well is about $440 \mathrm{~m}$ above mean sea level.

The main basement formation at the Nishiawakura observation well is granite. The well is of a flowing artesian type rich in radioactive minerals. As Rn concentration in the groundwater is very high (greater than $74 \mathrm{~Bq} /$ liter), the groundwater seems to flow through cracks in the granite, which is relatively rich in radioactive elements decaying to $\mathrm{Rn}$. The spring water ascends through a vertical uncased borehole from a depth of about $250 \mathrm{~m}$ [Earlier, I had reported that the borehole was cased (Koizumi, 1989). But the borehole was proved not to be cased after re-examination (Koizumi, 1991)]. The
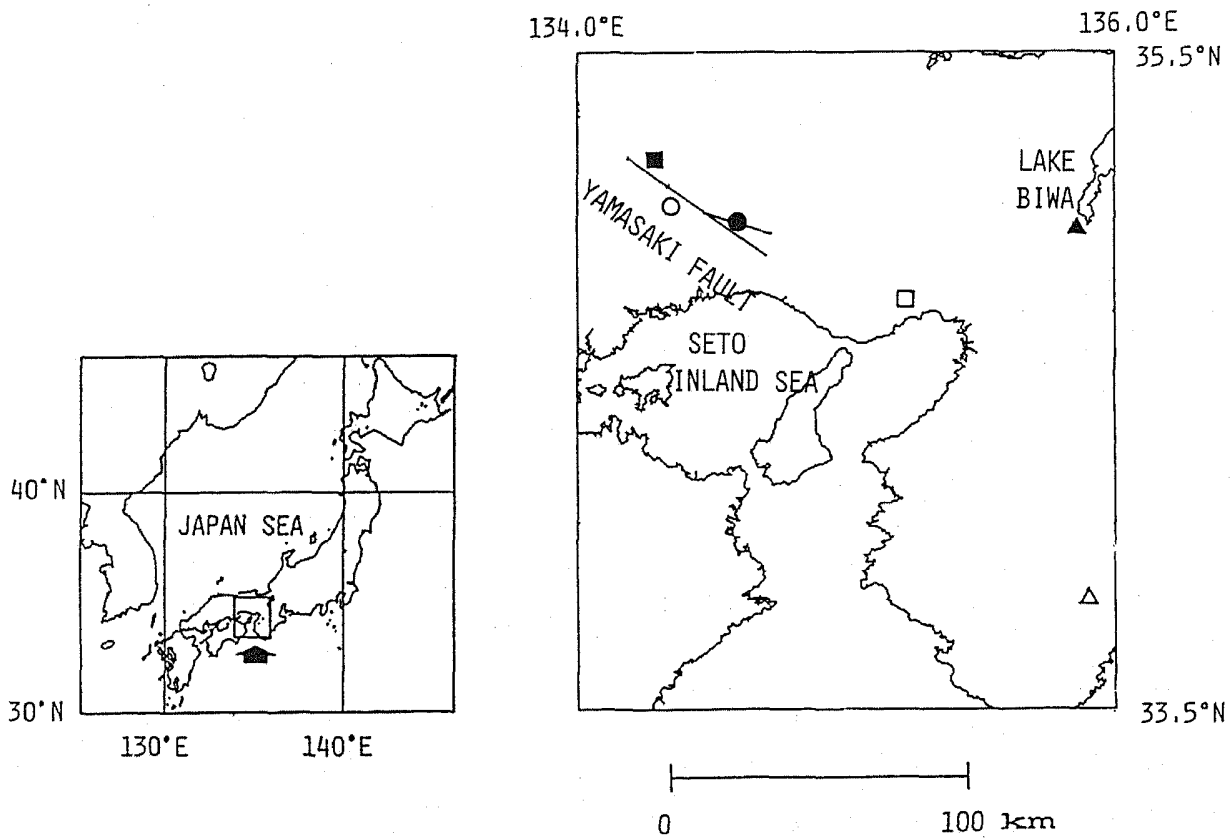

Fig. 1. Distribution of observation stations. The Nishiawakura observation well; , Yasutomi (Yamasaki Fault observation station) where atmospheric pressure is being measured; $O$, Sayo where rainfall is being measured; $\square$, The Rokko observation station; $\Delta$, The Osakayama observation station; $\Delta$, The Kishu observation station. 
principal source of groundwater which permeates into the borehole lies at a depth of about $50 \mathrm{~m}$ (Fig. 2). The water supply at other depths is nominal. This is supported by the fact that the ground temperature at the depth of $50 \mathrm{~m}$ (Fig. 3) was nearly equal to the water temperature of the observation well (Figs. 5 and 6).

It is assumed that the effects of the ocean tides are negligible at the Nishiawakura observation well because its distance from the ocean is more than $40 \mathrm{~km}$ (Fig. 1). The amplitudes of the tides in the Japan Sea and the Seto Inland Sea are relatively small and ocean tides have little effect on areal strain or volumetric strain except in coastal regions (Ozawa, 1957).

Figure 4 shows the setting for measuring the groundwater discharge at the observation well. The groundwater through the borehole with a diameter of $4.6 \mathrm{~cm}$, overflows into a $90^{\circ} \mathrm{V}$-notch weir, which is the same as those installed on small streams for measuring discharge (Wisler and Brater, 1959). The groundwater discharge is calculated from the level of water overflowing the weir. The water level changes were turned into electrical voltage changes by a float connected to a pulley which is linked to a variable electric resistance and these voltage changes were recorded. Resolution of the measurement system was better than $3.0 \mathrm{~cm}^{3} / \mathrm{s}$ for a range of the groundwater discharge between 200 and $500 \mathrm{~cm}^{3} / \mathrm{s}$. A thermistor was set at a depth of about $150 \mathrm{~cm}$. The electrical conductivity sensor was located just under the water exit. Resolution for temperature and conductivity measurements were $0.001{ }^{\circ} \mathrm{C}$ and $10 \mu \mathrm{S} / \mathrm{cm}$, respectively. These data were recorded on a point strip chart recorder, and the hourly values except the water temperature data were telemetered to Disaster Prevention Research Institute, Kyoto University.

Rainfall was not measured at the observation well. The observation system for the atmospheric pressure at the well did not always work well during the observation period. For the present investigation, I used the data of atmospheric pressure and rainfall obtained at Sayo and Yasutomi (Fig. 1), respectively.

In the following analysis, hourly values of these data were mainly used. The duration of the observation was 7 months-from September 26, 1987 to April 25, 1988.

\section{Observational Results}

The change of entire observational data and a typical change are shown in Figs. 5 and 6 , respectively. In these and subsequent figures, time is given in Japan Standard Time. Theoretical tidal volumetric strain at Nishiawakura is calculated from a homogeneous elastic earth model (Mikumo and Kato, 1976) under the assumption that the free surface boundary condition is applicable at a depth of $50 \mathrm{~m}$ and that the undrained Poisson's ratio is 0.25 . The discharge and the temperature of the groundwater clearly indicate similar periodic fluctuations (Fig. 6), which are both similar to those of the theoretical tidal volumetric strain. The tidal fluctuations in the temperature were considered to be caused by the tidal fluctuations of the discharge (Koizumi, 1989, 1991).

The discharge increased when the volumetric strain was compressive and decreased when the volumetric strain was tensile. This is reasonable and consistent with the reported tidal fluctuations of water levels at some static artesian wells.

Vol. 39, No. 6, 1991 


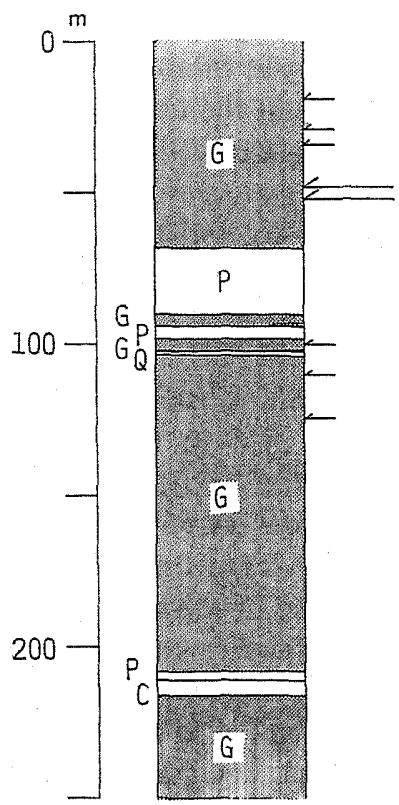

Fig. 2. Geological profile of the Nishiawakura observation well. This profile was obtained when the well was dug in 1970. Arrows indicate sources of groundwater permeating into the borehole. The two long arrows indicate the principal sources. G, granite; Q, quartz; P, porphyrite; C, clay.

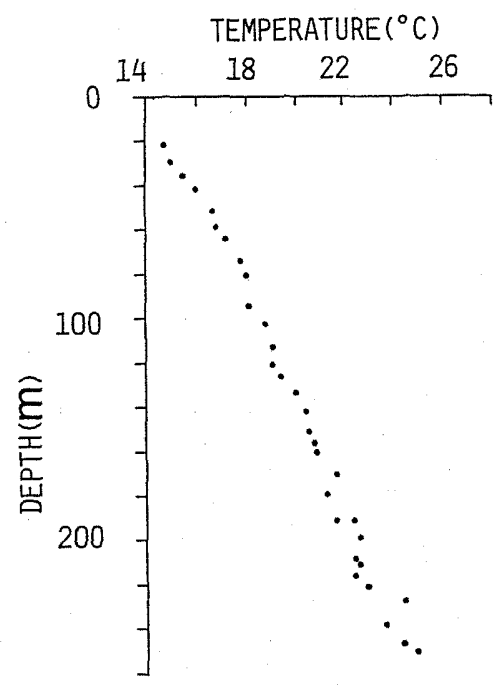

Fig. 3. Ground temperature profile of the Nishiawakura observation well. This profile was obtained when the well was dug in 1970. 


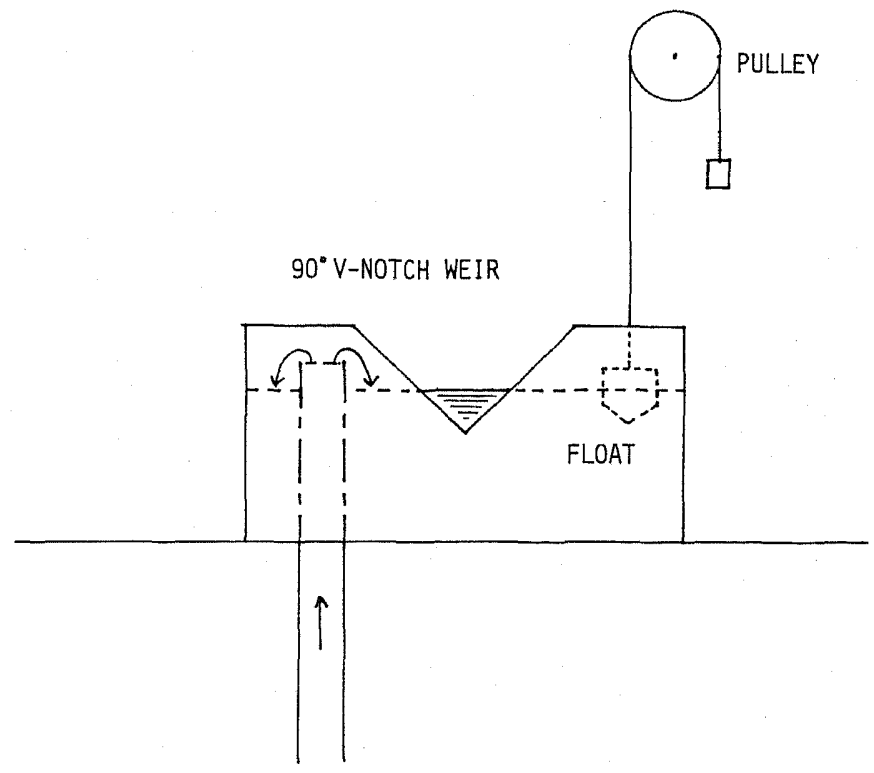

Fig. 4. Setting for measuring groundwater discharge at the Nishiawakura observation well. Arrows show the direction of the groundwater flow.

Although the atmospheric pressure seems to have an inverse correlation to groundwater discharge and water temperature, this was not always evident. The rainfall also might have had some effect on both the discharge and temperature. A heavy rainfall and a rapid change in atmospheric pressure caused by a typhoon in the middle of October 1987, possibly accelerated the groundwater discharge (Fig. 5). However, it is difficult to separate the effect of atmospheric pressure from that of rainfall because the rainfall is usually accompanied by a decrease in atmospheric pressure.

Electrical conductivity of the groundwater remained nearly constant during the observation period. In order to know whether the chemical components of the groundwater have tidal fluctuations or not, a sample of the groundwater was taken every hour at the same well from December 3, 1987 to December 4, 1987. The hourly changes in the concentration of major ions in these samples were nearly constant (Koizumi, 1989). If so, since the discharge has the tidal fluctuations, the net fluxes of the major ions in the groundwater show the identical tidal fluctuations.

Fourier analysis of the data of the discharge, the groundwater temperature, the atmospheric pressure and the atmospheric temperature was done as follows. I analyzed each 720 hourly data by the FFT method and took the mean of each Fourier amplitude. Almost all hourly data (7-months-long data from September 26, 1987) were used for this analysis except the groundwater temperature. As to the groundwater temperature, 5-months-long data from November 27, 1987 were used because of the defects of the groundwater temperature data (Fig. 5). This analysis of the groundwater 


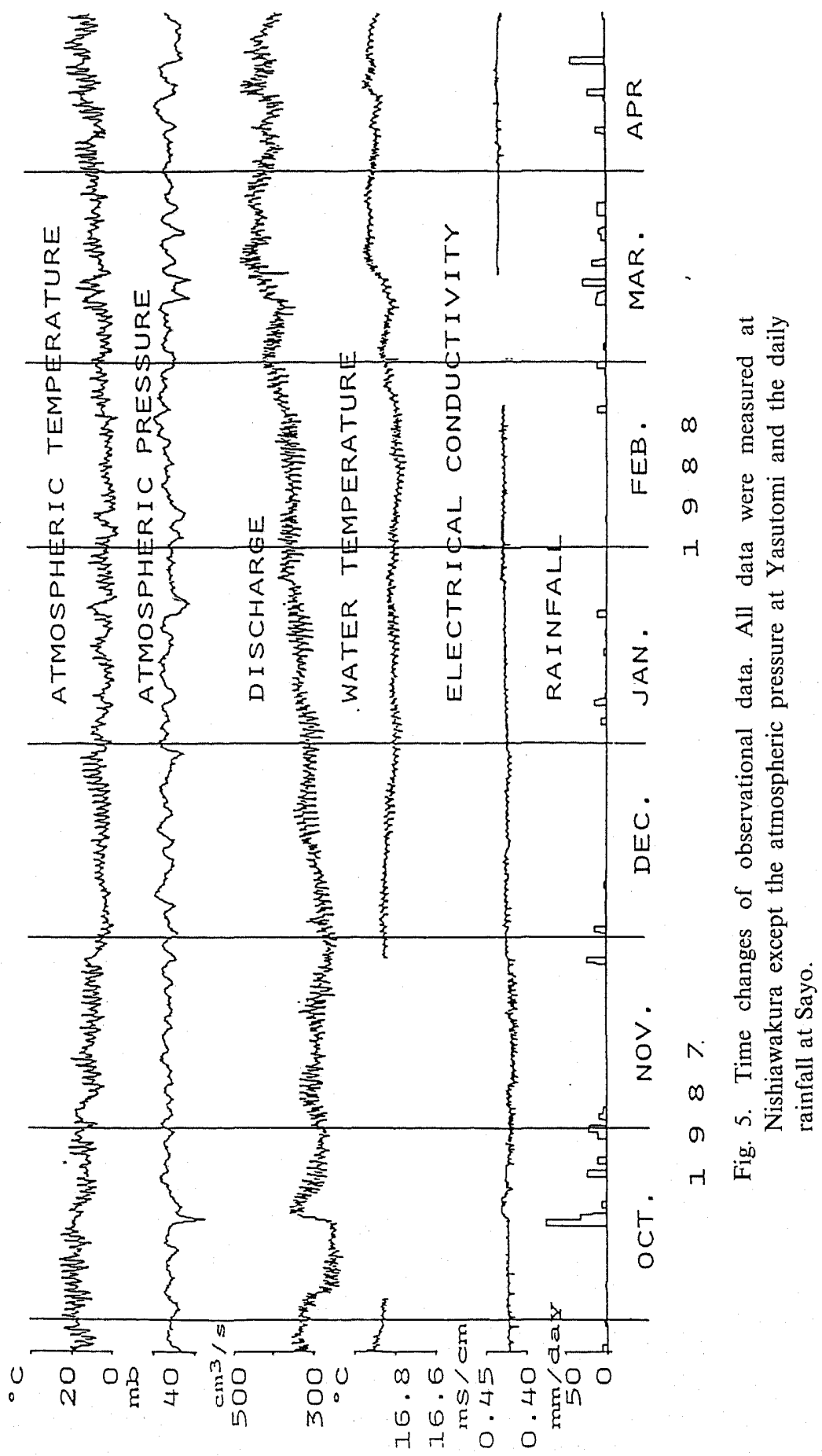

J. Phys. Earth 


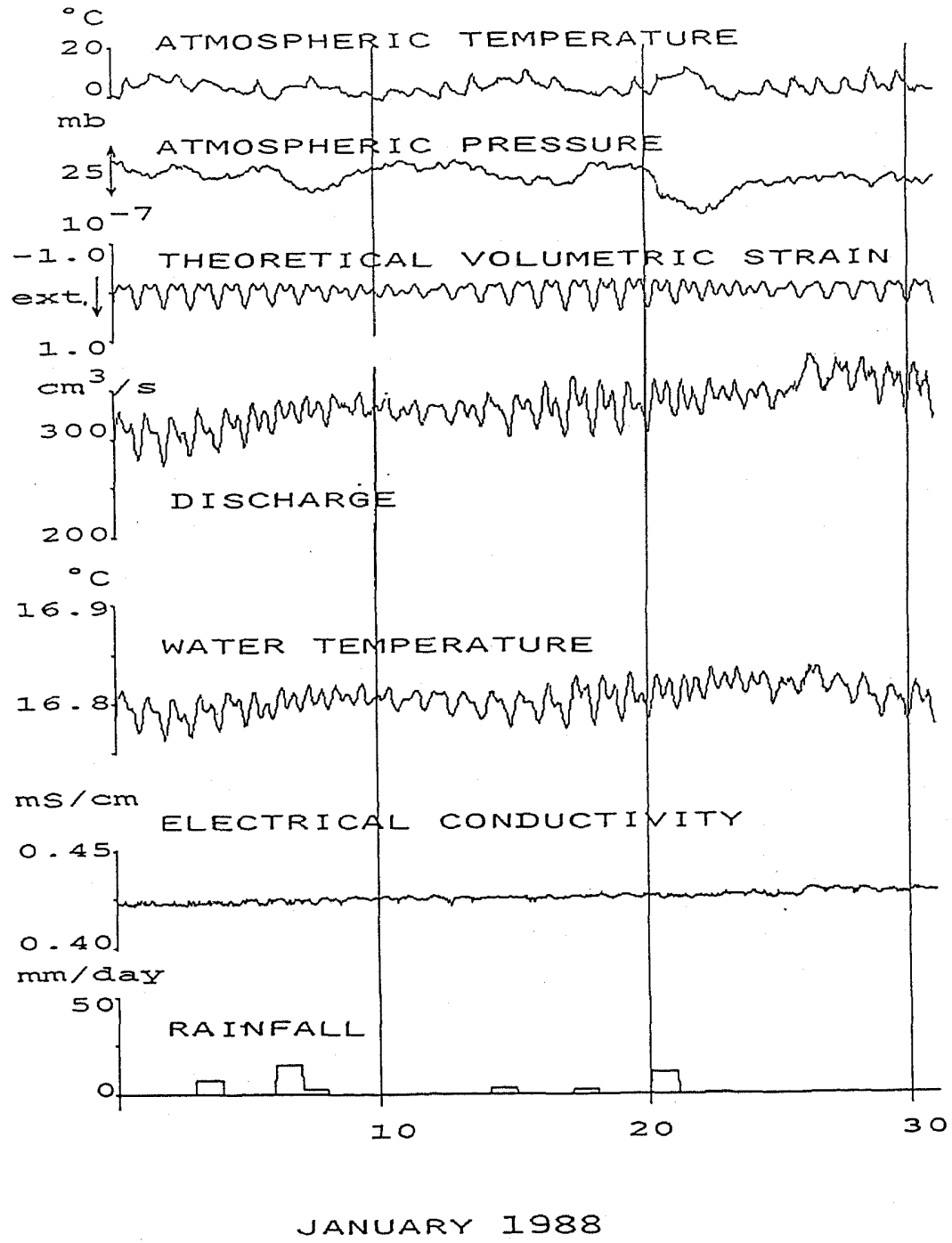

Fig. 6. Time changes of observational data and theoretical tidal volumetric strain at Nishiawakura in January 1988.

discharge and the temperature during the entire observation period clearly resolved into $\mathrm{M}_{2}$ and $\mathrm{O}_{1}$ components, which is typical of tidal phenomena (Fig. 7(a) and (b)). As was expected, the atmospheric pressure and temperature during the same period showed no $\mathrm{M}_{2}$ and $\mathrm{O}_{1}$ components (Fig. 7(c) and (d)).

The Fourier analysis ensured existence of the tidal component in the groundwater discharge. The amplitude and the phase of each main tidal component of the groundwater discharge were precisely determined using the hourly data for the entire

Vol. 39, No. 6, 1991 
(a)

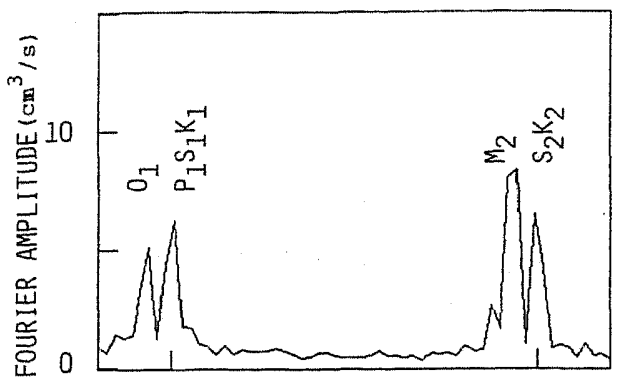

(b)

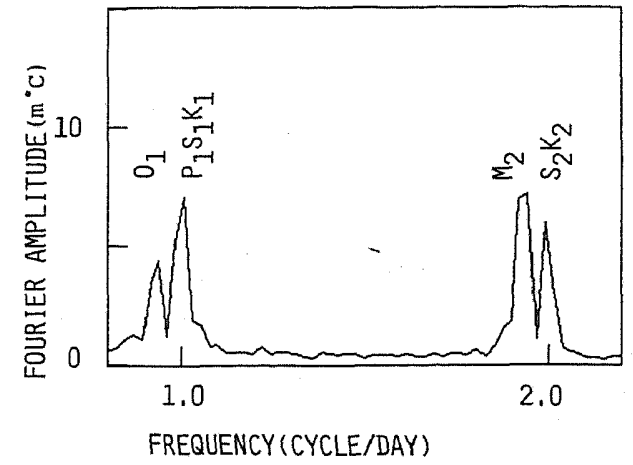

(c)

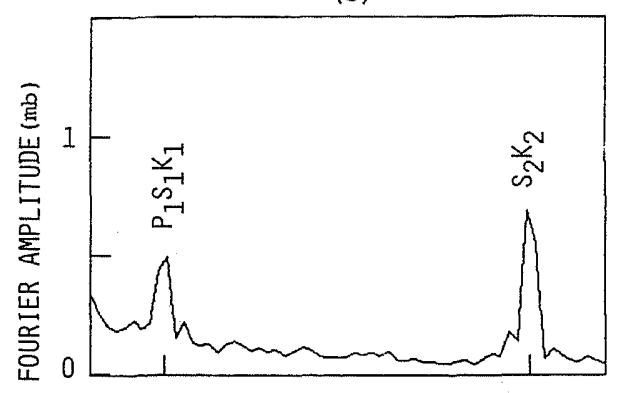

(d)

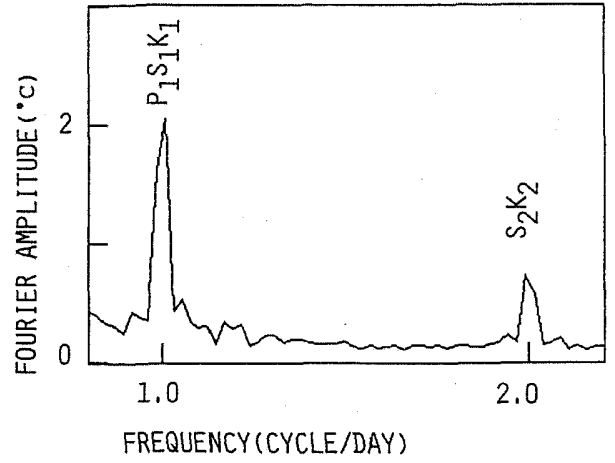

Fig. 7. Fourier spectra of (a) the groundwater discharge, (b) the groundwater temperature, (c) the atmospheric pressure, and (d) the atmospheric temperature.

Table 1. Tidal components of the groundwater discharge.

\begin{tabular}{lcccrc}
\hline $\begin{array}{c}\text { Tidal } \\
\text { component }\end{array}$ & $\begin{array}{c}\text { Period } \\
(\mathrm{h})\end{array}$ & $\begin{array}{c}\text { Frequency } \\
\text { (cycle/day) }\end{array}$ & $\begin{array}{c}\Delta_{0} \\
\left(10^{-8} \text { strain) }\right.\end{array}$ & $\begin{array}{c}Q_{\text {ta }} \\
\left(\mathrm{cm}^{3} / \mathrm{s}\right)\end{array}$ & $\begin{array}{c}\phi \\
\text { (deg.) }\end{array}$ \\
\hline $\mathrm{O}_{1}$ & 25.8 & 0.93 & 0.70 & $4.4(0.4)$ & $37.7(5.0)$ \\
$\mathrm{P}_{1} \mathrm{~S}_{1} \mathrm{~K}_{1}$ & $23.9-24.1$ & 1.00 & 0.99 & $5.7(0.3)$ & $45.4(3.4)$ \\
$\mathrm{M}_{2}$ & 12.4 & 1.94 & 1.20 & $10.2(0.1)$ & $17.2(0.7)$ \\
$\mathrm{S}_{2} \mathrm{~K}_{2}$ & 12.0 & 2.00 & 0.56 & $5.5(0.1)$ & $26.5(1.3)$ \\
\hline
\end{tabular}

$\Delta_{0}$ denotes amplitude of the tidal volumetric strain at the Nishiawakura observation well during the whole observation period from September 26, 1987 to April 25, 1988. $Q_{\mathrm{ta}}$ and $\phi$ respectively denote the amplitude and the phase shift of the discharge from the theoretical tidal volumetric strain. Figures in parentheses are respective standard deviations.

observation period and the Bayesian tidal analysis program (BAYTAP-G) developed by Ishiguro et al. (1984). On the basis of the theory of linear systems, the program assumes that the original data are composed of a trend, a component induced by associated non-tidal data, tidal components and some irregular noise. Each component 
$m b$

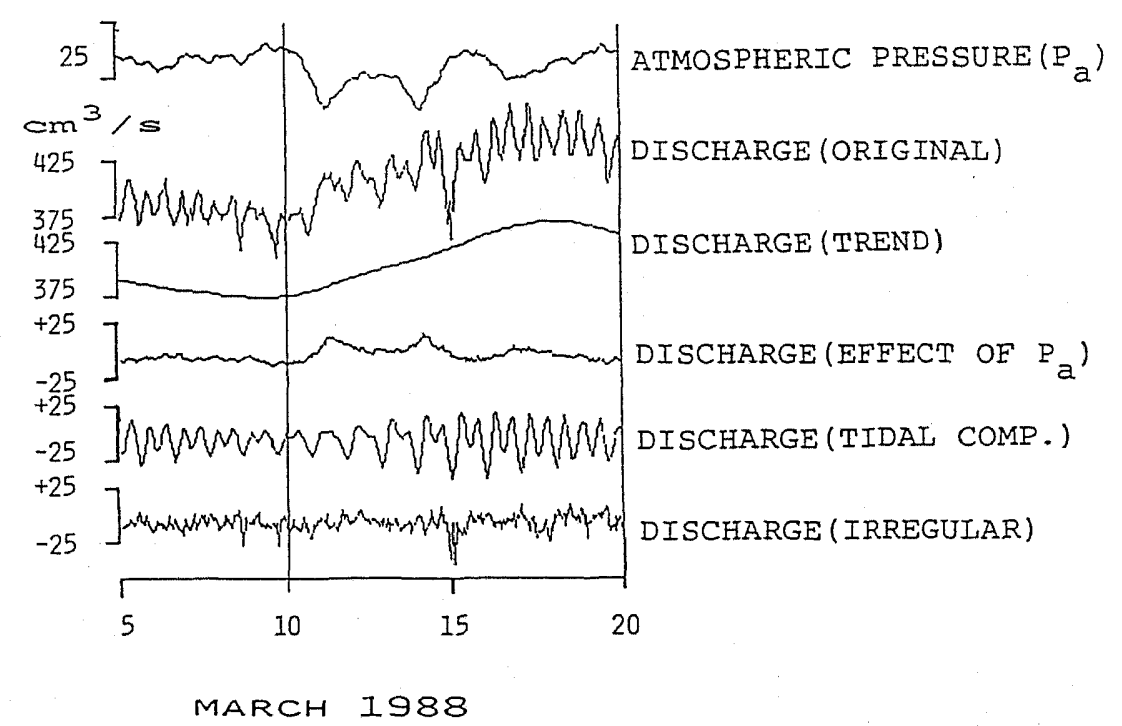

Fig. 8. Decomposition of the discharge calculated by BAYTAP-G.

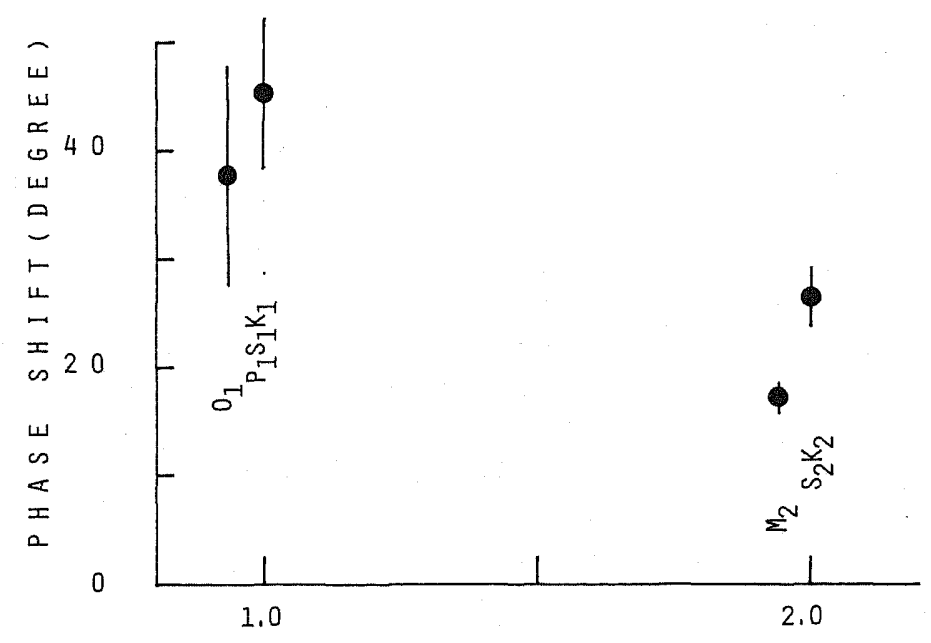

FREQUENCY ( C Y CLE/DAY)

Fig. 9. Phase shift of the groundwater discharge from the theoretical tidal volumetric strain. Bars show the error width, which is twice the respective standard deviation.

is calculated in the time domain when the Akaike's Bayesian information criterion (ABIC) is minimal (Ishiguro, 1981; Ishiguro et al., 1984). In the present case, the associated non-tidal data are the atmospheric pressure data at the Yasutomi

Vol. 39, No. 6, 1991 


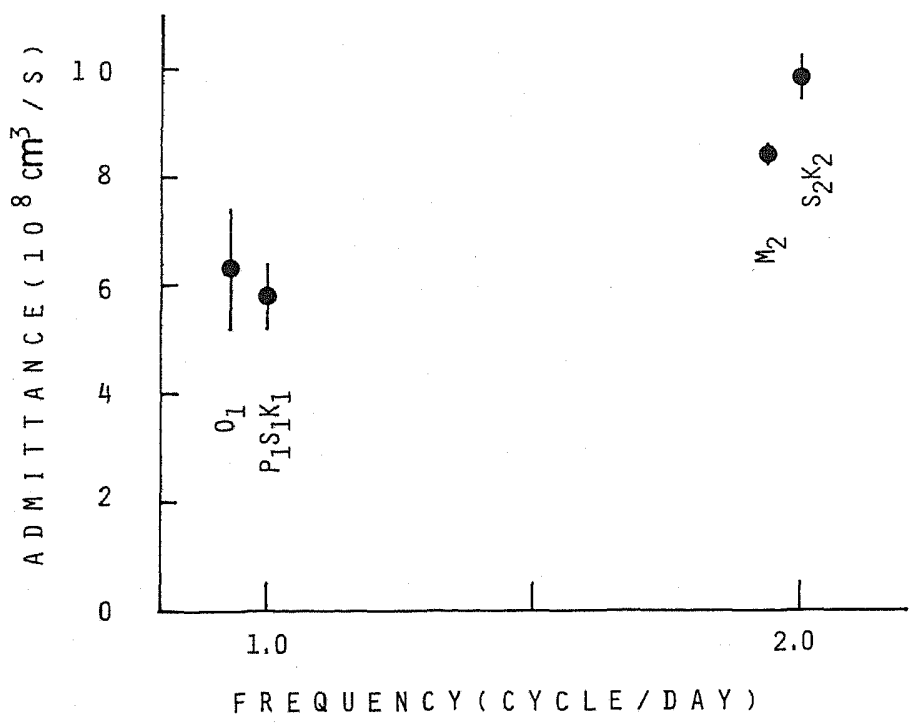

Fig. 10. Admittance between the groundwater discharge and the theoretical tidal volumetric strain. Bars show the error width, which is twice the respective standard deviation.

observation station, which are not always the same as those at the Nishiawakura observation well because the distance from the Nishiawakura observation well to the Yasutomi observation station is about $35 \mathrm{~km}$. But in the following analysis, the tidal components of the discharge during the whole observation period (Table 1) will be mainly used. Therefore, the difference in the atmospheric pressure can be taken as negligible. Figure 8 shows the decomposition of the discharge given by the analysis for a 15 day window (March 5-March 20, 1988).

Figures 9 and 10 show the phase shifts and admittances or spectral amplitude ratios of discharge to the theoretical volumetric strain. Note the relative phase advance of the groundwater discharge. In addition, the phase shifts for the diurnal frequency constituents $\left(\mathrm{O}_{1}\right.$ and $\left.\mathrm{P}_{1} \mathrm{~S}_{1} \mathrm{~K}_{1}\right)$ are greater than those for the semi-diurnal frequency constituents $\left(\mathrm{M}_{2}\right.$ and $\left.\mathrm{S}_{2} \mathrm{~K}_{2}\right)$. The admittance for the diurnal frequency constituents is smaller than that for the semi-diurnal frequency constituents. These will be explained in the following discussion.

\section{Discussion}

The investigation of the well water level response to the earth tides and atmospheric loading gave the following factors which explain the frequency dependence of the well water level response as

1. Horizontal flow between the observation well and the aquifer (Morland and Donaldson, 1984).

2. Tidal stress normal to the crack plains (where groundwater stays) when the 
cracks have a predominant orientation (Bower, 1983).

3. Horizontal flow in the horizontally inhomogeneous confined aquifer (Gieske and De Vries, 1985).

4. Vertical groundwater flow into and out of the partially confined aquifer (Rojstaczer 1988 a, b; Van der Kamp and Gale, 1983).

The first factor mainly explains the phase lag of the well water level response to the tidal strain. The second factor explains the case when the polarities of the phase for $\mathrm{O}_{1}$ and $\mathrm{M}_{2}$ components are different. Both the third and the fourth factors can explain the present case, that is, the phases for $\mathrm{O}_{1}$ and $\mathrm{M}_{2}$ components are both positive and the admittance for $\mathrm{O}_{1}$ component is smaller than that for $\mathrm{M}_{2}$ component.

If the aquifer of the Nishiawakura observation well is regarded as a partially confined aquifer, the fourth factor can be applied to the present case. But for applying the third factor, the following 3 conditions are needed (Gieske and De Vries, 1985).

1. The aquifer is horizontally inhomogeneous.

2. The inhomogeneity is expressed as a function of $r$, where $r$ is the distance from a certain point.

3. The function is equal to the Bessel function of the first kind of the order zero.

Clearly the fourth factor is more general and simpler. Therefore, the fourth factor is used in the following discussion.

Generally the groundwater in granite is kept in cracks. As the first approximation, because of a possible percolation of water into and away from the cracks, the cracks are regarded as a partially confined aquifer. The groundwater quality was considered to be almost constant during the observation period and the two principal groundwater sources are very close (Fig. 2). It was assumed that only one aquifer at the depth of $50 \mathrm{~m}$ supplies the water to the observation well.

Consider the water flow through a vertical borehole, as shown in Fig. 11. Let us

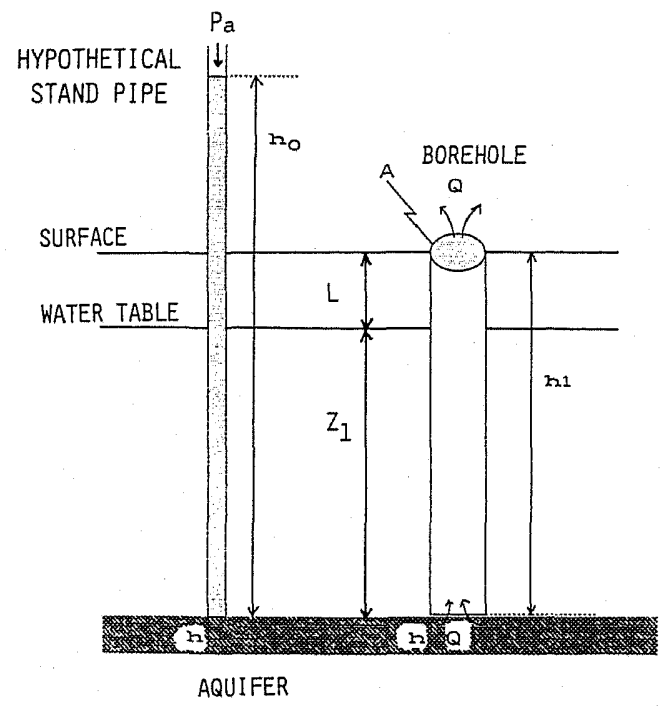

Fig. 11. Schematic figure of the groundwater flow through a vertical borehole.

Vol. 39 , No. 6, 1991 
assume that the groundwater in the borehole is incompressible. In order to apply the theory of the well water level to the well water discharge, the following empirical relation of Nomitsu et al. (1940) is introduced,

$$
Q=C A\left(h_{0}-h_{1}\right),
$$

where $Q$ is the groundwater discharge, $C$ is a constant specified for the borehole, $A$ is the cross section of the borehole, $h_{0}$ is the water level in the hypothetical stand pipe and $h_{1}$ is the depth of the aquifer or the distance between the top of the borehole and the top of the aquifer.

If $h$ is the pressure head in the aquifer,

$$
h=p / \rho g=h_{0}+P_{\mathrm{a}} / \rho g,
$$

where $p$ is the pore pressure, $\rho$ is the density of the groundwater, $g$ is the acceleration due to gravity and $P_{\mathrm{a}}$ is the atmospheric pressure.

Therefore, the groundwater discharge $(Q)$ can be expressed as

$$
Q=d_{1} p-d_{1} P_{\mathrm{a}}-d_{1} \rho g h_{1}
$$

and

$$
d_{1}=C A / \rho g .
$$

Equation (3) connects the discharge $(Q)$ to the pore pressure $(p)$. Equation (3) can also be regarded as Darcy's law. Therefore, the following discussion can be applied to general groundwater flow.

Under the free surface boundary condition with the undrained Poisson's ratio being 0.25 , the volumetric strain $(\Delta)$ is expressed as

$$
\Delta=2 \varepsilon / 3 \text {, }
$$

where $\varepsilon$ is the areal strain. According to Van der Kamp and Gale (1983) and Rojstaczer (1988 a), the pore pressure $(p)$ is related to the tidal areal strain $\left(\varepsilon_{\mathrm{a}}\right)$.

$$
\begin{gathered}
D_{1} \frac{\partial^{2} p}{\partial z^{2}}=\frac{\partial p}{\partial t}+\rho g A_{\mathrm{s}} \frac{\partial \varepsilon_{\mathrm{a}}}{\partial t}, \\
D_{1}=k / S_{\mathrm{s}},
\end{gathered}
$$

where $D_{1}$ is the hydraulic diffusivity for an imposed areal strain under conditions of plain stress, $z$ is vertical distance in coordinates, $t$ is time, $A_{\mathrm{s}}$ is the static confined areal strain sensitivity, $k$ is the hydraulic conductivity and $S_{\mathrm{s}}$ is the specific storage. The term $\left(D_{1}\left(\partial^{2} p / \partial z^{2}\right)\right)$ expresses the effect of vertical groundwater flow, or water table drainage. The response of the pore pressure $(p)$ to the imposed periodic areal strain $\left(\varepsilon_{0} \cos \omega t\right)$ was expressed as follows (Rojstaczer, 1988 a):

$$
\begin{aligned}
p= & \rho g A_{\mathrm{s}} \varepsilon_{0}\{\exp (-\sqrt{W}) \cos (\omega t-\sqrt{W})-\cos \omega t\} \\
= & -\rho g A_{\mathrm{s}} \varepsilon_{0} \sqrt{K^{2}+j^{2}} \cos (\omega t+\phi), \\
& j=1-\exp (-\sqrt{W}) \cos (\sqrt{W}) \quad(>0)
\end{aligned}
$$




$$
\begin{array}{cc}
K=\exp (-\sqrt{W}) \sin (\sqrt{W}) & (\geqq 0) \\
W=z_{1}^{2} \omega / 2 D_{1}=z_{1}^{2} \pi f / D_{1} & (>0) \\
\phi=\tan ^{-1}(K / j), & (\geqq 0)
\end{array}
$$
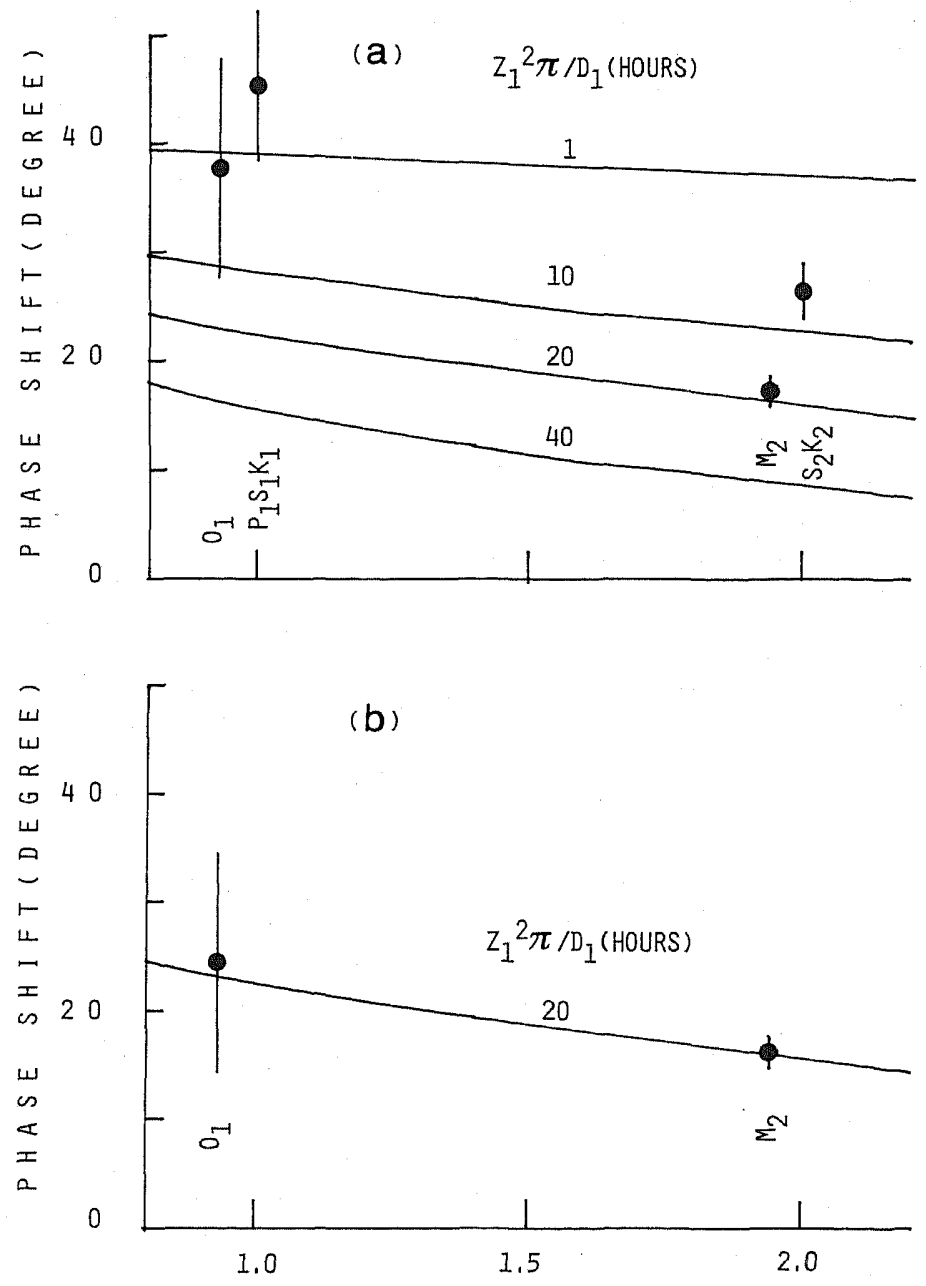

FREQUENCY(CYCLE/DAY)

Fig. 12. Comparison of the observational phase shifts (solid circles) to the theoretical ones (solid lines) when the value of the parameter $z_{1}{ }^{2} \pi / D_{1}$ in Eq. (11) is changed. (a) The phase difference between the theoretical tidal areal strain and the observed one (Table 2) is not considered. (b) The phase difference between the theoretical tidal areal strain and the observed one (Table 2) is considered only for $\mathrm{O}_{1}$ and $\mathrm{M}_{2}$ components.

Vol. 39, No. 6, 1991 
where $\omega$ is the angular frequency, $\phi$ is the phase shift, $f$ is the frequency and $z_{1}$ is the distance between the water table and the aquifer (Fig. 11). Equations (3) and (7) give

$$
Q_{\mathrm{t}}=-C A A_{\mathrm{s}} \varepsilon_{0} \sqrt{K^{2}+j^{2}} \cos (\omega t+\phi),
$$

where $Q_{t}$ is a tidal component of the discharge. The admittance or the spectral amplitude ratio of the discharge to the tidal areal strain becomes

$$
Q_{\mathrm{ta}} / \varepsilon_{0}=C A A_{\mathrm{s}} \sqrt{K^{2}+j^{2}},
$$

where $Q_{\mathrm{ta}}$ is the amplitude of the tidal discharge. The phase shift $(\phi)$ and the admittance $\left(Q_{\mathrm{ta}} / \varepsilon_{0}\right)$ are both frequency dependent. The phase shift $(\phi)$ is positive while dimensionless frequency $(W)$ is not equal to $n^{2} \pi^{2}$, where $n$ is an integer. The observed phase shifts of the discharge from the theoretical tidal areal strain are not well fitted for the theoretical ones calculated by Eq. (11) (Fig. 12(a)).

The Eqs. (11) and (13) are based on the assumption that the actual tidal areal strain in the aquifer is equal to the theoretical one. As Nishiawakura is located near a fault zone, the assumption needs to be examined. The tidal areal strain not being observed at Nishiawakura, those at the neighboring stations (monitoring crustal deformation),-Rokko, Osakayama, and Kishu (Fig. 1) were compared with theoretical strains for the $\mathrm{O}_{1}$ and $\mathrm{M}_{2}$ components (Table 2). The observed tidal areal strains at each station were obtained from the reports of Ozawa (1971) and Tanaka et al. (1972). The Rokko station is located in fractured zones whose basement is granite. The Osakayama station is far from the coast, as is Nishiawakura.

The phase differences between theoretical and observed tidal areal strains of the $\mathrm{M}_{2}$ component at each station is very small, but those of the $\mathrm{O}_{1}$ component is about 13 degrees and not negligible (Table 2). The tidal amplitude ratio of the observed areal

Table 2. Spectral amplitude ratios $(A R)$ and phase differences $(P D)$ between the theoretical

\begin{tabular}{|c|c|c|c|c|}
\hline $\begin{array}{c}\text { Tidal } \\
\text { component }\end{array}$ & Rokko & Osakayama & Kishu & Mean \\
\hline $\mathrm{O}_{1} A R$ & - & 1.18 & 0.47 & 0.83 \\
\hline$P D$ (deg.) & - & 13.2 & 13.2 & 13.2 \\
\hline $\mathrm{M}_{2} A R$ & $1.6-2.0$ & 0.92 & 0.32 & 1.0 \\
\hline$P R$ (deg.) & $2.0-9.5$ & 1.2 & -4.2 & 0.9 \\
\hline
\end{tabular}
tidal areal strains and the observed ones at neighboring stations.

Table 3. The parameter $C A A_{\mathrm{s}}$ in Eq. (13) estimated from the observational results when the parameter $z_{1}{ }^{2} \pi / D_{1}$ is $20 \mathrm{~h}$.

\begin{tabular}{cccccc}
\hline Tidal component & $\mathrm{O}_{1}$ & $\mathrm{P}_{1} \mathrm{~S}_{1} \mathrm{~K}$ & $\mathrm{M}_{2}$ & $\mathrm{~S}_{2} \mathrm{~K}_{2}$ & MEAN \\
\hline$C A A_{\mathrm{s}}\left(10^{8} \mathrm{~cm}^{3} / \mathrm{s}\right)$ & $5.2(0.5)$ & $4.7(0.2)$ & $5.9(0.1)$ & $6.8(0.1)$ & $5.7(0.2)$ \\
\hline
\end{tabular}

Figures in parentheses are the error widths when the respective standard deviations in Table 1 are regarded as the respective errors. 
strain to the theoretical one for the $\mathrm{O}_{1}$ component is a little larger than that for the $\mathrm{M}_{2}$ component at the same station (Table 2). Therefore, the difference of the ratio cannot explain that of the admittance in Fig. 10. If the same phase shifts between the theoretical and actual tidal areal strain at the Nishiawakura observation well exist, the observed phase shifts of the discharge to the actual areal strain are well fitted to the theoretical ones calculated by Eq. (11) and the parameter $z_{1}{ }^{2} \pi / D_{1}$ is estimated to be $20 \mathrm{~h}$ (Fig. 12(b)). Then the parameter $C A A_{\mathrm{s}}$ is calculated to be $5.7 \times 10^{8} \mathrm{~cm}^{3} / \mathrm{s}$ (Table 3) in the case where the tidal amplitude of the actual areal strain coincides with that of the theoretical one at the Nishiawakura observation well. Figure 13 illustrates that the observed admittance of the discharge to the tidal areal strain is also explainable by that calculated by Eq. (13). As for the $\mathrm{S}_{2} \mathrm{~K}_{2}$ component, the observed admittance

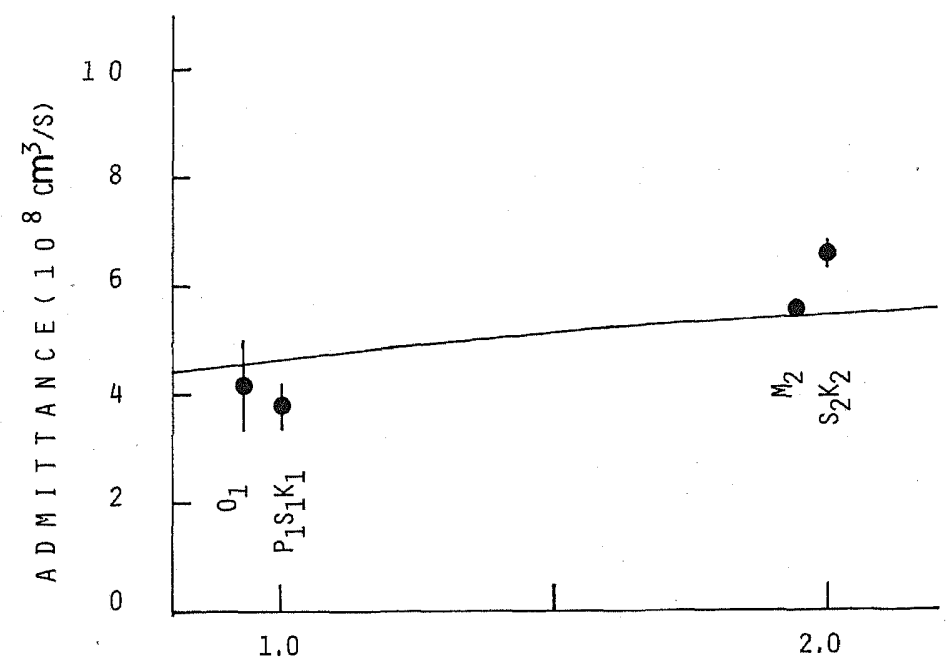

FREQUENCY (CYCLE/DAY)

Fig. 13. Comparison of the observational admittance (tidal amplitude ratio of the discharge to the tidal areal strain) and the theoretical one in the case where the parameters $z_{1}^{2} \pi / D_{1}$ and $C A A_{\mathrm{s}}$ are $20 \mathrm{~h}$ and $5.7 \times 10^{8} \mathrm{~cm}^{3} / \mathrm{s}$, respectively.

Table 4. Calculation of the parameter $C A=Q_{\mathrm{ta}} / L_{\mathrm{ta}}$.

\begin{tabular}{cccc}
$\begin{array}{c}\text { Tidal } \\
\text { component }\end{array}$ & $\begin{array}{c}Q_{\mathrm{ta}} \\
\left(\mathrm{cm}^{3} / \mathrm{s}\right)\end{array}$ & $\begin{array}{c}L_{\mathrm{ta}} \\
(\mathrm{cm})\end{array}$ & $\begin{array}{c}C A \\
\left(\mathrm{~cm}^{2} / \mathrm{s}\right)\end{array}$ \\
\hline $\mathrm{O}_{1}$ & $4.4(0.4)$ & $0.84(0.36)$ & $5.2(2.7)$ \\
$\mathrm{P}_{1} \mathrm{~S}_{1} \mathrm{~K}_{1}$ & $5.7(0.3)$ & $1.35(0.31)$ & $4.2(1.2)$ \\
$\mathrm{M}_{2}$ & $10.2(0.1)$ & $2.32(0.14)$ & $4.4(0.3)$ \\
$\mathrm{S}_{2} \mathrm{~K}_{2}$ & $5.5(0.1)$ & $1.27(0.11)$ & $4.3(0.5)$ \\
\hline
\end{tabular}

Figures in parentheses denote standard deviations $\left(Q_{\mathrm{ta}}\right.$ and $\left.L_{\mathrm{ta}}\right)$ or the error widths $(C A)$ when regarding the respective standard deviations of $Q_{\mathrm{ta}}$ and $L_{\mathrm{ta}}$ as their respective errors. $L_{\mathrm{ta}}$ denotes the tidal amplitude of the groundwater level observed for 18 days from January 23, 1987 to February 9, 1987. 
differs significantly from the calculated one. This possibly results from the fact that the effect of atmospheric pressure on the discharge is not sufficiently eliminated by BAYTAP-G.

The depth of the water table $(L)$ is about $5 \times 10^{2} \mathrm{~cm}$ and $z_{1}$ is taken to be $4.5 \times 10^{3} \mathrm{~cm}$. Therefore, $D_{1}$ is estimated to be $8.8 \times 10^{2} \mathrm{~cm}^{2} / \mathrm{s}$. In order to calculate $A_{\mathrm{s}}$, the value of $C A$ in Eq. (13) must be estimated. The tidal fluctuations of the groundwater level in the same well were monitored for 18 days, from January 23 to February 9 1987, and each tidal component was estimated (Table 4). The error is minimal for the $\mathrm{M}_{2}$ component in Table 4 and the values of $C A$ and $d_{1}$ were estimated as $4.4 \mathrm{~cm}^{2} / \mathrm{s}$ and $4.3 \mathrm{~cm}^{3} / \mathrm{s} \cdot \mathrm{mb}$, respectively. Therefore, $A_{\mathrm{s}}$ was calculated to be $1.3 \times 10^{8} \mathrm{~cm} / \mathrm{strain}$. The values of $D_{1}$ and $A_{\mathrm{s}}$ seem to be consistent with those given by Rojstaczer (1988 b) and Rojstaczer and Agnew (1989).

\section{Conclusion}

1. Tidal fluctuations of the groundwater discharge induced by the earth tides were observed at the Nishiawakura observation well. Their phase shifted forward from the tidal strain. The phases and admittances for the diurnal frequency constituents were different from those for the semi-diurnal frequency constituents.

2. This frequency dependence of the discharge can be well explained by the response theory of a partially confined aquifer to the tidal strain, which was carefully investigated by Rojstaczer (1988 a).

3. It became clear that the theory can also be applied to the real groundwater movement induced by the variation of crustal strain. As strain-induced groundwater movement is considered to have close relation to geothermal and geochemical precursors to earthquakes, the theory is expected to be useful for studying the mechanism of such precursors.

I am grateful to Dr. Y. Kishimoto for his helpful advice. I am much indebted to Dr. R. Yoshioka, Dr. K. Okunishi, Dr. T. Tanaka, and Dr. R. Ghose for many encouraging discussions on this subject. I wish to thank Dr. K. Watanabe and S. Matsuo for their field assistance and discussions. I also wish to thank two anonymous reviewers for their helpful advice.

\section{REFERENCES}

Bower, D. R., Bedrock fracture parameters from the interpretation of well tides, J. Geophys. Res., 88, 5025-5035, 1983.

Bredehoeft, J. D., Response of well-aquifer systems to earth tides, J. Geophys. Res., 72, 3075-3087, 1967.

Gieske, A. and J. J. De Vries, An analysis of earth-tide-induced groundwater flow in eastern Botswana, J. Hydrol., 82, 211-232, 1985.

Igarashi, G. and H. Wakita, Tidal responses and earthquake-related changes in the water level of deep wells, J. Geophys. Res., 96, 4269-4278, 1991.

Ishiguro, M., A bayesian approach to the analysis of the data of crustal movements, J. Geod. Soc. Jpn., 27, 256-262, 1981 . 
Ishiguro, M., T. Sato, Y. Tamura, and M. Ooe, Tidal data analysis-An introduction to BAYTAP-, Proceedings of the Institute of Statistical Mathematics, 32, 71-85, 1984 (in Japanese).

Kishimoto, Y., On precursory phenomena observed at the Yamasaki Fault, Southwest Japan, as a test-field for earthquake prediction, in Earthquake Prediction-An International Review Maurice Ewing Ser. 4, pp. 510-516, AGU, 1981.

Koizumi, N., Analysis of chemical composition and temperature of the groundwater having a flow rate fluctuation induced by earth tides, Proceedings of the Japan-China (Taipei) Joint Seminar on Natural Hazard Mitigation, 67-76, 1989.

Koizumi, N., Analysis of groundwater temperature variation of artesian well fluctuated by the earth tides, Zisin, Ser 2, 44, 155-164, 1991 (in Japanese).

Melchior, P., Die gezeiten in unterirdischen flussigkerten, Erdoel Kohle, 13, 312-317, 1960.

Melchior, P., The Tides of the Planet Earth (2nd ed.), Pergamon Press, Oxford, 641pp., 1983.

Mikumo, T. and M. Kato, Time domain analysis of earth tide records, Bull. Disas. Prev. Res. Inst., Kyoto Univ., 26, 71-81, 1976.

Morland, L. W. and E. C. Donaldson, Correlation of porosity and permeability of reservoirs with well oscillations induced by earth tides, Geophys. J. R. Astron. Soc., 79, 705-725, 1984.

Nomitsu, T., K. Seno, and K. Yamashita, The correlation between the rate of discharge and the pressure head in the Beppu hot springs (1. The stratified type), Mem. Coll. Sci., Kyoto Univ., Ser. A, 23, 75-95, 1940.

Ozawa, I., Study on elastic strain of the ground in earth tides, Bull. Disas. Prev. Res. Inst., Kyoto Univ., 15, 1-36, 1957.

Ozawa, I., An expression of the anisotropy of the earth tidal strains, J. Geod. Soc. Jpn., 17, 85-93, 1971 (in Japanese).

Rhoads, G. H., Jr. and E. S. Robinson, Determination of aquifer parameters from well tides, $J$. Geophys. Res., 84, 6071-6082, 1979.

Robinson, E. W. and R. T. Bell, Tides in confined well-aquifer systems, J. Geophys. Res., 76, 1857-1869, 1971.

Rojstaczer, S., Intermediate period response of water levels in wells to crustal strain: Sensitivity and noise level, J. Geophys. Res., 93, 13619-13634, 1988 a.

Rojstaczer, S., Determination of fluid flow properties from the response of water levels in wells to atmospheric loading, Water Resour. Res., 24, 1927-1938, 1988 b.

Rojstaczer, S. and D. C. Agnew, The influence of formation material properties on the response of water levels in wells to earth tides and atmospheric loading, J. Geophys. Res., 94, 12403-12411, 1989.

Tanaka, Y., M. Hayashi, M. Kato, and K. Huzita, Continuous observation of crustal deformations in a fracture zone of Rokko fault system (first report), Annu. Disas. Prev. Res. Inst., Kyoto Univ., 15B, 29-41, 1972 (in Japanese).

Van der Kamp, G. and J. E. Gale, Theory of earth tide and barometric effects in porous formations with compressible grains, Water Resour. Res., 19, 538-544, 1983.

Wisler, C. O. and E. F. Brater, Hydrology, John Wiley \& Sons, Inc., New York, 408pp., 1959.

Vol. 39, No. 6, 1991 